Kruijsen-Terpstra, A.J.A., Ketelaar, M., Boeije, H., Jongmans, M.J., Gorter, J.W., Verheijden, J.. Lindeman, E., Verschuren, O. Parents' experiences with physical and occupational therapy for their young child with cerebral palsy: a mixed studies review. Child: Care, Health and Development: 2014, 40(6), 787-796

\begin{tabular}{|c|c|}
\hline $\begin{array}{l}\text { Postprint } \\
\text { Version }\end{array}$ & 1.0 \\
\hline Journal website & $\begin{array}{l}\text { http://onlinelibrary. wiley.com/doi/10.1111/cch.12097/abstract;jsessionid=945B19 } \\
\text { F0193D3DFC6279E55738AE9BE9.f01 t02 }\end{array}$ \\
\hline Pubmed link & http://www.ncbi.nlm.nih.gov/pubmed/?term=23937711 \\
\hline DOI & $10.1111 /$ cch.12097 \\
\hline
\end{tabular}

This is a NIVEL certified Post Print, more info at http://www.nivel.eu

\title{
Parents' experiences with physical and occupational therapy for their young child with cerebral palsy: a mixed studies review
}

\author{
A. J. A. KRUIJSEN-TERPSTRA, ${ }^{*} \dagger$ M. KETELAAR, ${ }^{*} \dagger$ H. BOEIJE, $\$$ M. J. JONGMANS,$\dagger \S$ IJ.W. \\ GORTER, $\dagger^{* *}$, J. VERHEIJDEN,,$\dagger$ E. LINDEMAN* AND O. VERSCHUREN*† \\ *Brain Center RudolfMagnus and Center of Excellence for \\ RehabilitationMedicine,UniversityMedical Center Utrecht and DeHoogstraat \\ Rehabilitation, Utrecht, the Netherlands \\ †Partner of NetChild, Network for Childhood Disability Research in the Netherlands, Utrecht, \\ the Netherlands \\ ¥Utrecht University, Utrecht, the Netherlands \\ §University Medical Center Utrecht, Wilhelmina Children's Hospital, Department of \\ Neonatology, Utrecht, the Netherlands \\ qUtrecht University, Faculty of Social Sciences, Department of Pedagogical and Educational \\ Sciences, Utrecht, the Netherlands \\ ${ }^{* *}$ CanChild Centre for Childhood Disability Research, McMaster University, Hamilton, \\ Ontario, Canada, and \\ ††BOSK, Association of people with cerebral palsy, Utrecht, the Netherlands
}

\begin{abstract}
Understanding the experiences of parents with their child's intervention might help meet the needs of parents and, subsequently get them engaged in their child's intervention. As parents' early beliefs regarding their child's intervention has consequences for treatment participation, it is important to understand these parental perspectives. The aim of this mixed studies review was to give an overview of the experiences and related factors of parents of young children $(0$ 5 years of age) with cerebral palsy in relation to the physical and/or occupational therapy of their child in a rehabilitation setting. The literature was searched systematically for qualitative and quantitative studies published between January 1990 and July 2011. Inclusion criteria were (1) the study population consisted of parents of children with cerebral palsy, with at least $25 \%$ of children under the age of five; (2) children had received physical and/or occupational therapy in a rehabilitation setting; and (3) the experiences of the parents with their child's therapy were addressed. Data were synthesized with the framework synthesis method resulting in a conceptual framework describing the factors that are related to the parents' experiences with their child's interventions. A total of 13 studies (eight qualitative and five quantitative) were
\end{abstract}


Kruijsen-Terpstra, A.J.A., Ketelaar, M., Boeije, H., Jongmans, M.J., Gorter, J.W., Verheijden, J.. Lindeman, E., Verschuren, O. Parents' experiences with physical and occupational therapy fo their young child with cerebral palsy: a mixed studies review. Child: Care, Health and Development: 2014, 40(6), 787-796

included and evaluated. Parents expressed various aspects in context, process and outcomes when asked about their experiences with their child's intervention. They had different needs over time and needed time to build a collaborative relationship with their child's therapists. The proposed framework acknowledges the various aspects in context, process and outcomes that parents reported when asked about their experiences. Knowing this, the importance of the broader context of the child in a family should be acknowledged; realizing the impact that the demands of daily life, supports and resources provided to parents, attitudes in the community and culture have on parental experiences.

\section{INTRODUCTION}

Children with cerebral palsy (CP) typically receive physical and or occupational therapy, with the goal of promoting performance and participation in daily life activities. Traditionally, physical and occupational therapists used to focus on the child's impairments and limitations (Bly 1991). The therapist acted as the primary decision-maker and parents had a passive role in their child's therapy (Bazyk 1989). Since the 1980s the traditional treatment paradigm has shifted towards a focus on the functional abilities of the child in daily life. The family needs in addition to the child's needs became increasingly important. Currently a family-centred approach (Bamm \& Rosenbaum 2008) is a key concept in the treatment of children with CP and their families (Gorter 2009), with partnership and collaboration being the principal aspects of care (Kuo et al. 2012). Today, parents and therapists ideally decide on goals and fulfil the intervention as equal partners, i.e. shared goal setting and decision-making (Bamm \& Rosenbaum 2008). The shift from patient focused to family-centred care is not only noticed in physical and occupational therapy, but also in general paediatric care for children with disabilities or other special health care needs (Arango 2011).

Family-centred interventions in a rehabilitation setting typically imply active engagement of families (Whyte \& Hart 2003). For young children this means that therapists should take in consideration the ability of parents, primary caregivers and other family members to actively engage. It is known from research on child behaviour problems that parent ideas about treatment may be especially important in determining treatment participation, as parents typically are responsible for initiating treatment, providing consent and payment, and ensuring treatment attendance (Nock et al. 2007). It is also suggested that parent beliefs about their child's treatment very early on in the process could have a significant impact on treatment participation and consequently on outcomes (Nock et al. 2007).

Parents are more satisfied when interventions are applied in a family-centred manner (King et al. 1996). Every family is unique with different preferences for their child's care (Nijhuis et al. 2007). Information regarding parent perspectives may inform clinical practice and service delivery, therefore facilitating changes in services that align with family needs and maximize opportunities for their engagement in rehabilitation. Given that early parental beliefs regarding their child's intervention has consequences, it is important to understand the perspectives of parents of young children with CP. So far there are only a few quantitative and qualitative studies on the experiences of this specific group of parents. In this article we will conduct a mixed studies review by including qualitative as well as quantitative studies to 
Kruijsen-Terpstra, A.J.A., Ketelaar, M., Boeije, H., Jongmans, M.J., Gorter, J.W., Verheijden, J. Lindeman, E., Verschuren, O. Parents' experiences with physical and occupational therapy fo their young child with cerebral palsy: a mixed studies review. Child: Care, Health and Development: 2014, 40(6), 787-796

answer the following questions: (i) what are the experiences of parents of young children ( $0-5$ years of age) with CP in relation to the physical and/or occupational therapy of their child in a rehabilitation setting; and (ii) which factors are related to these experiences?

\section{METHOD}

\section{Search}

The databases PubMed, Psychinfo, Embase and Cinahl were searched for studies published between January 1990 and July 2011 with search terms of 'child', 'cerebral palsy', 'parent', 'experience' and 'intervention'. Appendix I provides an expansion on all terms entered in PubMed. The exact search string was adapted for each database.

\section{Study selection and data extraction}

The resulting studies were screened to assess whether they met the following inclusion criteria: (1) the study population consisted of parents of children with $\mathrm{CP}$, studies included in this analysis had at least $25 \%$ of children under the age of $5 ;$ (2) children had received physical and/or occupational therapy in a rehabilitation setting; and (3) the experiences of the parents with their child's therapy were addressed. Qualitative as well as quantitative studies were included. The first selection of studies was based on title and abstract by the first author (AK). Thereafter the remaining studies were read full-text by both the first author (AK) and the second author (MK). Studies that met all the inclusion criteria were included in this review. Data of the included studies were extracted by two of the authors (AK, MK).

\section{Quality appraisal}

The methodological quality of the included qualitative and quantitative studies was assessed with the Critical Review form - Qualitative Studies (version 2.0) and the Critical Review form - Quantitative Studies respectively (Law et al. 1998; Letts et al. 2007). Both forms come with accompanying guidelines. The original dichotomous format of these forms has no scoring system. Therefore the scoring system according to Lekkas and colleagues (2007) was applied. In cases in which a critical appraisal criterion was addressed adequately, a score of one point was awarded. If the criterion was not, or insufficiently addressed a score of zero was awarded. Using this approach, the maximum possible score was 14 points for either quantitative or qualitative studies. To ensure that the appraisal of the methodological quality of the study was consistent, the first three qualitative studies were appraised by four of the authors (AK, MK, HB, OV). The differences were limited to an acceptable maximum of two points. Thereafter, the remaining studies were discussed and appraised by two of the authors (AK, MK).

\section{Synthesis}

Data were synthesized with the framework synthesis method (Barnett-Page \& Thomas 2009). In this approach an existing model from the literature is used as a framework against which the data from the included studies are mapped. This framework can then be built upon, expanded upon, reduced or added to by these new data (Carroll et al. 2011). In the literature, no suitable model of parent experiences with their child's intervention was available. Therefore, we used the 'best-fit' model approach by Carroll and colleagues (2011) in which a model from the literature that 
Kruijsen-Terpstra, A.J.A., Ketelaar, M., Boeije, H., Jongmans, M.J., Gorter, J.W., Verheijden, J. Lindeman, E., Verschuren, O. Parents' experiences with physical and occupational therapy for their young child with cerebral palsy: a mixed studies review. Child: Care, Health and Development: 2014, 40(6), 787-796

best suits the subject of the study is used even though it does not fully correspond nivel with the subject. The Family-Centred Care model as described by Arango (2011) was used as the 'best-fit' model (Fig. 1). This model provides the possibility to describe parent perspectives on their child's intervention regarding context, process and outcomes.

\section{[FIGURE 1]}

From the included studies, only findings from the Results section of each study were analysed. Sandelowski and Barroso (2002) defined findings as 'data based and integrated discoveries, judgments, or pronouncements researchers had offered about the experiences'. The data were synthesized following a stepwise approach. In step 1, data were extracted independently by two of the authors (AK, MK). From the quantitative studies we extracted the variables that were related to the parent experiences, variables that were associated with parent experiences were not included. Themes from the qualitative studies were not copied one-to-one, but were labelled so they could serve to create new themes. From both these variables and labels a new list of themes was constructed. In step 2, the extent to which the themes of the 'best-fit' model were supported by the extracted data was checked.

Furthermore, the new themes that emerged from the data extraction were debated. Finally, in step 3, a conceptual framework was developed to describe the factors that were related to the parents' experiences with their child's interventions.

\section{RESULTS}

\section{Search}

The search in the four databases resulted in a total of 701 references (Fig. 2). After removing the duplicates a total of 417 articles were left. The title and abstract of each article was read as a screening procedure. This resulted in 401 articles being rejected because of a lack of description of the experiences of parents with their child's intervention, or the child's intervention was neither physical nor occupational therapy. The remaining 16 articles were read in full text, three of these were excluded based on the content of their full text. A total of 13 articles were included in this review, eight qualitative studies and five quantitative studies. Recorded features of included studies are presented in Table 1.

\section{[FIGURE 2]}

\section{[TABLE 1]}

\section{Quality of the studies}

Quality appraisal explored the nature and quality of the evidence of the articles. The median quality score for the eight qualitative studies was 10 points out of the 14point scale (range 5-12). The median quality score for the five quantitative studies was nine points out of the 14-point scale (range 5-12 points). Despite a score of five points in three studies, it was felt that it was still worth including them. These studies were awarded, for example, a score of zero on items for not reporting obtaining informed consent (Hinojosa \& Anderson 1991) or for not reporting avoiding cointerventions (Bower \& McLellan 1994; Chan et al. 2005) which may have been 
Kruijsen-Terpstra, A.J.A., Ketelaar, M., Boeije, H., Jongmans, M.J., Gorter, J.W., Verheijden, J. Lindeman, E., Verschuren, O. Parents' experiences with physical and occupational therapy fo their young child with cerebral palsy: a mixed studies review. Child: Care, Health and Development: 2014, 40(6), 787-796

conducted but not reported. Scores of the quality appraisal for each study can be found in Table 1.

\section{Summarizing and synthesis}

The themes with elucidation, as derived in step 1, are presented in Table 2. This table reports the number of studies reflected as well as if the theme is supported by a quantitative or/and qualitative study.

\section{[TABLE 2]}

\section{Context}

The contextual aspects of the 'best-fit' model, family and community, were both supported by the included studies. The subthemes that were added to family and support from others at community were support from family, shared responsibilities and roles within family.

Based on the synthesis the framework was extended to include a cultural aspect and demands of daily life. Parents expressed a struggle with the balance between therapy and demands of everyday life. This was especially true when parents had more children. In these cases the child's therapy influenced family life and could be experienced as a stressor.

\section{Process}

Of the process aspects of the 'best-fit' model, the family-professional partnership, shared decision-making, respect and trust by partners, and open communication were supported by the included studies. Only willingness to negotiate was not supported. Based on the synthesis the framework was further elaborated with several new themes on process and family-professional partnership, and extended with intervention. In relation to the process, parents expressed the need for co-ordinated care, comprehensive care, continuity of care, information and wanted the therapist to have dedicated time with their child.

In relation to the family-professional partnership, parents wanted to share their responsibilities with the therapists, and to collaborate with them, especially in goal setting. Furthermore parents expressed the importance of enabling parents to make own decisions, and the need and importance of receiving support from the therapists. Moreover, parents said that they needed time to develop the relationship with their child's therapist.

With regard to the process aspects of the interventions themselves, parents mentioned that they tried to implement their child's intervention at home and to integrate goals in everyday life, but sometimes did this partly by adapting the intervention or self-selecting which parts they integrated because of difficulties with implementing the intervention at home. Furthermore, parents expressed the importance of the therapist-child relationship with the therapist understanding their child. In relation to the intervention design, parents expressed that an intensive training programme should allow a time of rest and no therapy between sessions. With regard to the intervention content, parents said that they got engaged in implementation by interventions that set short-term, realistic, small and achievable goals. Even though therapists and parents had different perspectives on goals, many goals that were important in the school setting did not reflect family priorities. 
Kruijsen-Terpstra, A.J.A., Ketelaar, M., Boeije, H., Jongmans, M.J., Gorter, J.W., Verheijden, J.. Lindeman, E., Verschuren, O. Parents' experiences with physical and occupational therapy fo their young child with cerebral palsy: a mixed studies review. Child: Care, Health and Development: 2014, 40(6), 787-796

\section{Outcomes}

The outcome aspects of the 'best-fit' model that were supported by the included studies were improved child health and well-being, increased access and satisfaction with care. Only cost savings was not supported.

Based on the synthesis, the outcome aspects of the framework were extended to include negative child outcomes, and both positive as well as negative parental outcomes. Parents in an intensive group training study reported a negative outcome in their child's well-being, the intense nature of the programme caused fatigue in their children. Progress and improvement in the their own confidence, motivation, competence and acquired knowledge and understanding created positive parental experiences. Furthermore, their child's intervention resulted in a widened perspective, increased participation in the community, increased time with the child, gave parents the opportunity to share experiences with other parents, caused parents to become increasingly effective in goal setting, and to see progress. On the other hand parents expressed negative outcomes as feelings of insufficiency, guilt and a lack of confidence. Parents lost hope when goals were not reached.

\section{Overall}

On the basis of the list of themes in combination with the 'best-fit' model of Arango (2011) the framework, as presented in Fig. 3, was generated with the framework synthesis method (step 3). The framework displays the various factors that are related to the experiences of parents of young children ( $0-5$ years of age) with $\mathrm{CP}$ in relation to the physical and/or occupational therapy of their child in a rehabilitation setting and acknowledges contextual, process and outcome aspects.

\section{[FIGURE 3]}

Parents in the study of Piggot and colleagues (2002) expressed that they had different needs over time. In the beginning, parents expressed a state of unreadiness to be involved in therapy of their child, they needed time to develop a relationship with their child's therapist. The framework, therefore, is a dynamic one.

The arrows in the 'best-fit' model suggested directed relations. However, the literature on parental experiences did not reveal evidence for the direction of these relations. Therefore, the proposed framework based on these experiences has connectors indicating that the contextual, process and outcome aspects are interrelated and indicate the dynamic entity of the framework, but give no explicit direction to the relationship between the aspects.

\section{DisCUSSION}

The purpose of this review was to give an overview of the experiences and the factors related to these experiences of parents of young children ( $0-5$ years of age) with $\mathrm{CP}$ in relation to the physical and/or occupational therapy of their child in a rehabilitation setting. Through a mixed studies review we gained a more complete overview. For example, the need for co-ordinated and comprehensive care, and the differences between experiences of mothers and father were only reflected in the quantitative studies. The demands of everyday life that parents experienced, on the other hand, were only reflected in the qualitative studies. The quantitative and qualitative studies were complementary to each other. Even though the 'best-fit' 
Kruijsen-Terpstra, A.J.A., Ketelaar, M., Boeije, H., Jongmans, M.J., Gorter, J.W., Verheijden, J. Lindeman, E., Verschuren, O. Parents' experiences with physical and occupational therapy for their young child with cerebral palsy: a mixed studies review. Child: Care, Health and Development: 2014, 40(6), 787-796

model approach by Carroll and colleagues (2011) is originally designed to synthesize qualitative data, we were able to integrate the data of both study types by this approach. The proposed framework, as generated with the framework synthesis method, acknowledges the various factors in context, process and outcomes that parents reported when asked about their experiences. Being aware of all these factors helps therapists to meet the needs of parents and, subsequently, getting parents engaged in their child's intervention.

The realization of the 'best-fit' model by Arango (2011) is not clearly based on evidence and definitions or elucidations of the themes are lacking. Except for two, all of the original themes of the 'best-fit' model were supported by the literature reviewed in this study. The themes 'willingness to negotiate' and 'cost savings' were not supported by the included studies. It is possible that the original theme 'willingness to negotiate' corresponds with our theme 'shared decision-making', as these themes are quite similar. However, the rationale for the term 'willingness to negotiate' is lacking in Arango (2011). It seems reasonable that parents did not report cost savings when they were asked to share their experiences on their child's interventions. The systematic analysis of the literature elaborated the model with themes like the need for information, the adaption process of parents over time, and parental outcomes that were related to their child's intervention.

We would like to stress that the framework as constructed in this review is not a static, but a dynamic entity which can vary according to where parents are in their process of adapting to having a child with a disability. This adaption process, as described by Piggot and colleagues (2002) and later by Rentinck and colleagues (2007), found that parent adaptation was related to change in their child's development and in stages of family life over time. Similarly, Darrah and colleagues (2012) also noted that preferences of families may change over time.

Even though most parents expressed that they appreciated to be involved in their child's interventions and to collaborate with the therapists (Hinojosa \& Anderson 1991; Piggot et al. 2002; Øien et al. 2010; Wiart et al. 2010; Morgan \& Tan 2011), some parents also expressed a negative side of this involvement. Parents reported, for example, feelings of insufficiency and lack of confidence. In reaching a true collaboration, trust and honesty are important prerequisites; otherwise, parents might just keep up appearances (Piggot et al. 2002). In addition, parents expressed that they needed time to develop a relationship with their child's therapist (Piggot et al. 2002). As every family is unique, each has different preferences for how the collaboration is established (Nijhuis et al. 2007). This is supported by a study on perspectives of family-centred care, showing that the process of determining the role of parents in their child's care was often not a true collaborative, even though family-centred care is known for its emphasis on the family-professional partnership (MacKean et al. 2005).

The content of the physical and occupational therapy interventions was different for most studies, even though part of parental reports were similar regardless of the type of intervention the children received. Apparently, some of the experiences of parents are more general and exceeded the precise therapy content.

In most studies the role of the parent in the child's intervention was not well described, but this role was possibly also not well defined. This makes it difficult to interpret the results in relation to the specific aspects of therapy. The degree of parental involvement might have influenced parent experiences. 
Kruijsen-Terpstra, A.J.A., Ketelaar, M., Boeije, H., Jongmans, M.J., Gorter, J.W., Verheijden, J. Lindeman, E., Verschuren, O. Parents' experiences with physical and occupational therapy fo their young child with cerebral palsy: a mixed studies review. Child: Care, Health and Development: 2014, 40(6), 787-796

Not all studies reported if the mother or the father of the child shared their experiences. In the studies where it was reported (Hinojosa 1990; Piggot et al. 2002; Ahl et al. 2005; Ödman et al. 2009; Christy et al. 2010; Øien et al. 2010; Wiart et al. 2010), in most cases more mothers than fathers participated in the study. Possibly this has influenced the reported experiences because Ahl and colleagues (2005) found that fathers and mothers report differently. This is also supported by Pelchat and colleagues (2009), who found that mothers and fathers of young children with $\mathrm{CP}$ have different views on the situation. In addition to realizing that every family is unique, therapists should also realize that every family member is unique each having their own needs and perspectives, which can change over time. In future research on parent experiences the possible differences between mothers and fathers should be addressed in more detail.

There was a lack of studies focusing specifically on experiences of parents of young children with CP; only three of the 13 included studies solely including parents of children aged 0-5 years. Unfortunately, not all studies distinguished between experiences of parents of younger and older children with CP. As the adaptation process of parents seemed to be important for parents' experiences (Piggot et al. 2002), it could be that our results are influenced by the experiences of parents of older children with CP. More studies specifically examining the experiences of parents of young children with $\mathrm{CP}$ are needed.

This review focused on the experiences of parents of children with CP. However, it is possible that these experiences are also transferable to parents of children with other physical disabilities. For, most of the experiences that were reported were related to family-centred care principles that can be applied irrespectively of the child's diagnosis. Therefore, the aspects that were expressed by the parents of children with CP might exceed diagnosis.

Professionals working with young children should be aware of the importance of the family-professional partnership and the time it takes to build a collaborative relationship with parents. Furthermore it should be realized that every family and each member of the family is unique and might have different preferences in this collaboration. Defining roles and tasks of both therapists and family members should be a joint process in which preferences may vary over time. With this, the importance of the broader context of the child in a family should be acknowledged, realizing the influence that the demands of daily life, supports and resources provided to parents, and attitudes in the community and culture have on the experiences of parents of children with $\mathrm{CP}$.

\section{Acknowledgements}

This research was financially supported by ZonMw, Johanna Kinderfonds, Stichting Rotterdams Kinderrevalidatie Fonds Adriaanstichting, Revalidatiefonds, Phelps

Stichting, Revalidatie Nederland and the Nederlandse Vereniging van

Revalidatieartsen. The authors are thankful to Floryt van Wesel and Silvia Rietdijk for their contribution to the initial literature search, and to Nick Rademacher for his efforts in correcting the English text.

APPENDIX: APPENDIX I: USED SEARCH TERMS

\section{REFERENCES}

Ahl, L. E., Johansson, E., Granat, T. \& Carlberg, E. B. (2005) Functional therapy for children with cerebral palsy: an ecological approach. Developmental Medicine and Child Neurology, 47 , 
Kruijsen-Terpstra, A.J.A., Ketelaar, M., Boeije, H., Jongmans, M.J., Gorter, J.W., Verheijden, J. Lindeman, E., Verschuren, O. Parents' experiences with physical and occupational therapy for their young child with cerebral palsy: a mixed studies review. Child: Care, Health and Development: 2014, 40(6), 787-796

613-619.

Arango, P. (2011) Family-centered care. Academic Pediatrics, 11, 97-99.

Bamm, E. L. \& Rosenbaum, P. (2008) Family-centered theory: origins, development, barriers, and supports to implementation in rehabilitation medicine. Archives of Physical Medicine and Rehabilitation, 89, 1618-1624.

Barnett-Page, E. \& Thomas, J. (2009) Methods for the synthesis of qualitative research: a critical review. BMC Medical Research Methodology, 9, 59.

Bazyk, S. (1989) Changes in attitudes and beliefs regarding parent participation and home programs: an update. The American Journal of Occupational Therapy: Official Publication of the

American Occupational Therapy Association, 43, 723-728.

Bly, L. (1991) A historical view and current view of the basis of NDT. Pediatric Physical Therapy, 3, 131-135.

Bower, E. \& McLellan, D. L. (1994) Assessing motor-skill acquisition in four centres for the treatment of children with cerebral palsy. Developmental Medicine \& Child Neurology, 36, 902-909.

Carroll, C., Booth, A. \& Cooper, K. (2011) A worked example of "best fit" framework synthesis: a systematic review of views concerning the taking of some potential chemopreventive agents. BMC Medical Research Methodology, 11, 29.

Chan, H. S., Lau, P. H., Fong, K. H., Poon, D. \& Lam, C. C. (2005) Neuroimpairment, activity limitation, and participation restriction among children with cerebral palsy in Hong Kong. Hong Kong Medical Journal = Xianggang Yi Xue Za Zhi/Hong Kong Academy of Medicine, 11, 342-350.

Christy, J. B., Saleem, N., Turner, P. H. \& Wilson, J. (2010) Parent and therapist perceptions of an intense model of physical therapy. Pediatric Physical Therapy, 22, 207-213.

Darrah, J., Wiart, L., Magill-Evans, J., Ray, L. \& Andersen, J. (2012) Are family-centred principles, functional goal setting and transition planning evident in therapy services for children with cerebral palsy? Child: Care, Health and Development, 38, 41-47.

Gorter, J.W. (2009) Rehabilitative therapies for the child with cerebral palsy: focus on family, function and fitness. Minerva Pediatrica, 61, 425-440.

Hinojosa, J. (1990) How mothers of preschool children with cerebral palsy perceive occupational and physical therapists and their influence on family life. Occupational Therapy Journal of Research, 10, 144-160.

Hinojosa, J. \& Anderson, J. (1991) Mothers' perceptions of home treatment programs for their preschool children with cerebral palsy. The American Journal of Occupational Therapy: Official Publication of the American Occupational Therapy Association, 45, 273-279.

King, S. M., Rosenbaum, P. L. \& King, G. A. (1996) Parents' perceptions of caregiving: development and validation of a measure of processes. Developmental Medicine and Child Neurology, 38, 757-772.

Kuo, D. Z., Houtrow, A. J., Arango, P., Kuuhlthau, K. A., Simmons, J. M. \& Neff, J. M. (2012) Family-centred care: current applications and future directions in pediatric health care. Maternal and Child Health Journal, 16, 297-305.

Law, M., Stewart, D., Pollock, N., Letts, L., Bosch, J. \& Westmorland, M. (1998) Critical review form - quantitative studies. Available at: http://www.canchild.ca/en/canchildresources/resources/quanreview_form1.doc (last accessed April 2012).

Lekkas, P., Larsen, T., Kumar, S., Grimmer, K., Nyland, L., Chipchase, L., Jull G., Buttrum P., Carr L. \& Finch, J. (2007) No model of clinical education for physiotherapy students is superior to another: a systematic review. The Australian Journal of Physiotherapy, 53,19 28.

Letts, L., Wilkins, S., Law, M., Stewart, D., Bosch, J. \& Westmorland, M. (2007) Critical review form - qualitative studies (version 2.0). Available at: http://www.srsmcmaster.ca/Portals/20/pdf/ebp/qualreview_version2.0.pdf (last accessed April 2012).

MacKean, G. L., Thurston, W. E. \& Scott, C. $\bar{M}$. (2005) Bridging the divide between families and health professionals' perspectives on family-centred care. Health Expectations: An International Journal of Public Participation in Health Care and Health Policy, 8, 74-85. 
Kruijsen-Terpstra, A.J.A., Ketelaar, M., Boeije, H., Jongmans, M.J., Gorter, J.W., Verheijden, J. Lindeman, E., Verschuren, O. Parents' experiences with physical and occupational therapy for their young child with cerebral palsy: a mixed studies review. Child: Care, Health and Development: 2014, 40(6), 787-796

Morgan, F. \& Tan, B. K. (2011) Rehabilitation for children with cerebral palsy in rural Cambodia: parental perceptions of family-centred practices. Child: Care, Health and Development, 37, 161-167.

Nijhuis, B. J., Reinders-Messelink, H. A., de Blecourt, A. C., Hitters, W. M., Groothoff, J.W., Nakken, H. \& Postema, K. (2007)Family-centred care in family-specific teams. Clinical Rehabilitation, 21, 660-671.

Nock, M. K., Ferriter, C. \& Holmberg, E. (2007) Parent beliefs about treatment credibility and effectiveness: assessment and relation to subsequent treatment participation. Journal of Child and Family Studies, 16, 27-38.

Ödman, P., Krevers, B. \& Öberg, B. (2007) Parents' perceptions of the quality of two intensive training programmes for children with cerebral palsy. Developmental Medicine \& Child Neurology, 49, 93-100.

Ödman, P., Richt, B. \& Öberg, B. (2009) Parent's conceptions of intensive group training. The case of cerebral palsy. Disability and Rehabilitation, 31, 293-301.

Øien, I., Fallang, B. \& Østensjø, S. (2010) Goal-setting in paediatric rehabilitation: perceptions of parents and professional. Child: Care, Health and Development, 36, 558565.

Pelchat, D., Levert, M. J. \& Bourgeois-Guerin, V. (2009) How do mothers and fathers who have a child with a disability describe their adaptation/transformation process? Journal of Child Health

Care: For Professionals Working with Children in the Hospital and Community, 13, 239-259.

Piggot, J., Paterson, J. \& Hocking, C. (2002) Participation in home therapy programs for children with cerebral palsy: a compelling challenge. Qualitative Health Research, 12, 1112-1129.

Rentinck, I. C., Ketelaar, M., Jongmans, M. J. \& Gorter, J.W. (2007) Parents of children with cerebral palsy: a review of factors related to the process of adaptation. Child: Care, Health and Development, 33, 161-169.

Sandelowski, M. \& Barroso, J. (2002) Finding the findings in qualitative studies. Journal of Nursing Scholarship: An Official Publication of Sigma Theta Tau International Honor Society of

Nursing/Sigma Theta Tau, 34, 213-219.

Whyte, J. \& Hart, T. (2003) It's more than a black box; it's a Russian doll: defining rehabilitation treatments. American Journal of Physical Medicine \&

Rehabilitation/Association of Academic

Physiatrists, 82, 639-652.

Wiart, L., Ray, L., Darrah, J. \& Magill-Evans, J. (2010) Parents' perspectives on occupational therapy and physical therapy goals for children with cerebral palsy. Disability \&

Rehabilitation, 32,

248-258. 
Kruijsen-Terpstra, A.J.A., Ketelaar, M., Boeije, H., Jongmans, M.J., Gorter, J.W., Verheijden, J. Lindeman, E., Verschuren, O. Parents' experiences with physical and occupational therapy for their young child with cerebral palsy: a mixed studies review. Child: Care, Health and Development: 2014, 40(6), 787-796

\section{TABLES AND FIGURES}
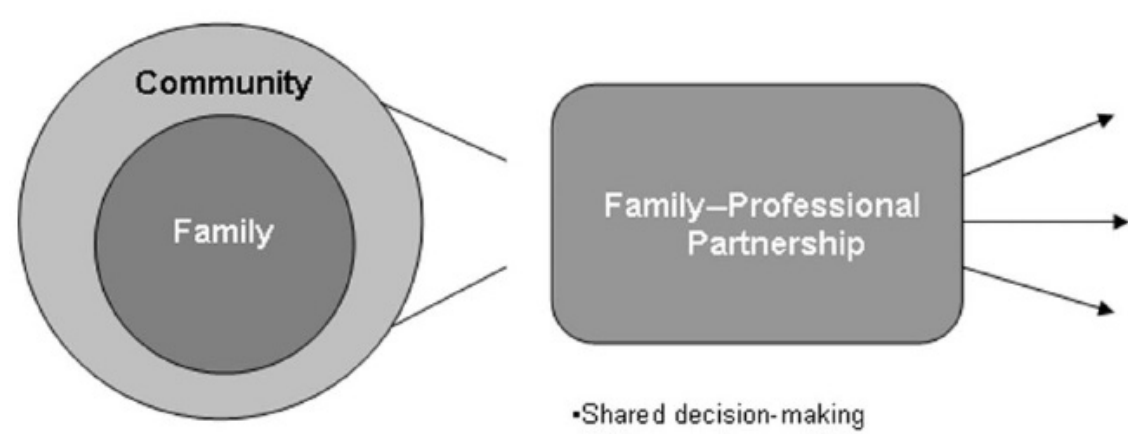

Improved Child

Health and

Well-being

Increased

Access and

Satisfaction

with Care

-Shared decision-making

- Willingness to negotiate

Cost Savings

-Respect and trust by partners

- Open communication

\section{Context}

\section{Process}

Outcomes

Figure 1. Context, process and outcomes of Family-Centred Care (Arango 2011). 
Kruijsen-Terpstra, A.J.A., Ketelaar, M., Boeije, H., Jongmans, M.J., Gorter, J.W., Verheijden, J. Lindeman, E., Verschuren, O. Parents' experiences with physical and occupational therapy for their young child with cerebral palsy: a mixed studies review. Child: Care, Health and Development: 2014, 40(6), 787-796

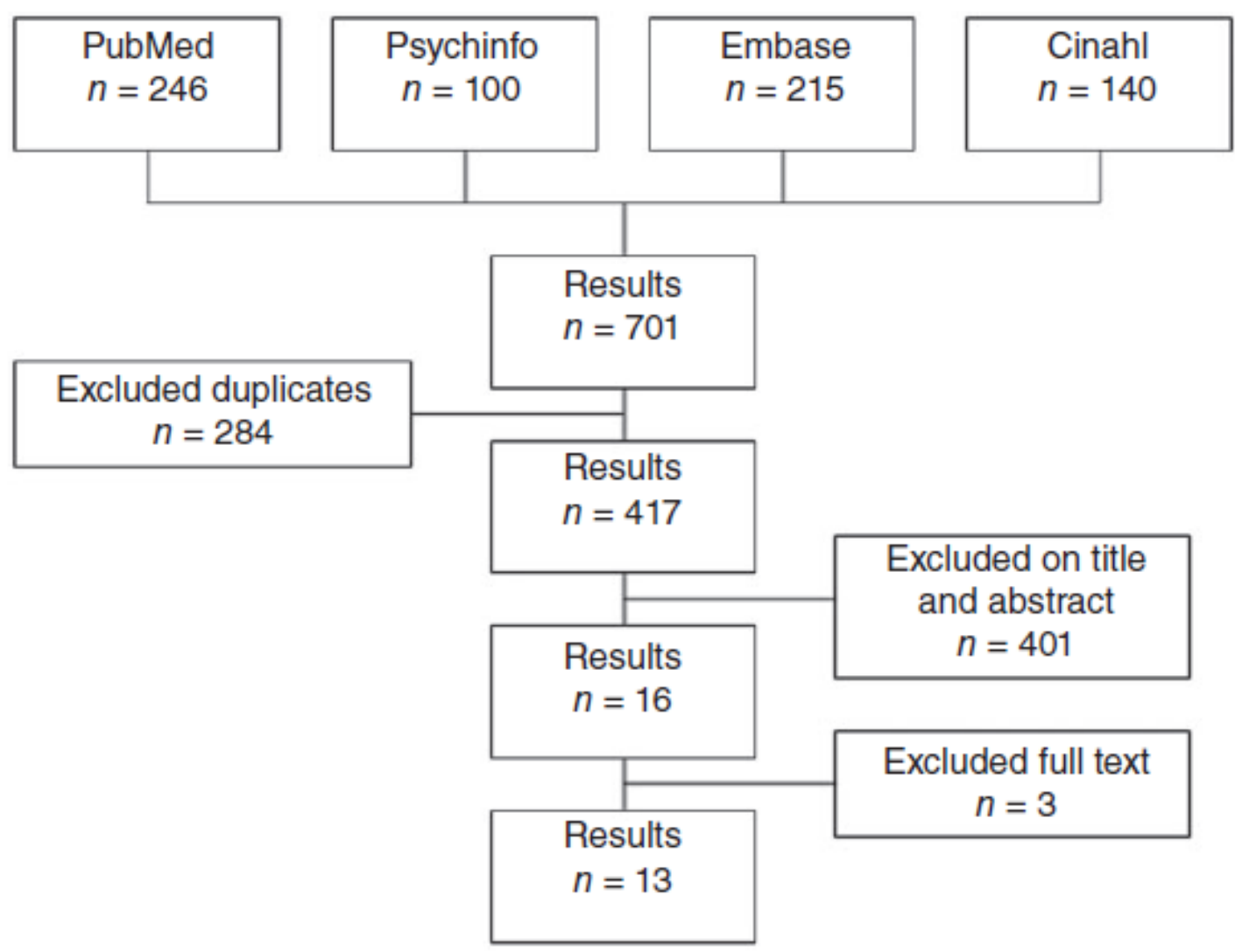

Figure 2. Flowchart of study selection. 
Kruijsen-Terpstra, A.J.A., Ketelaar, M., Boeije, H., Jongmans, M.J., Gorter, J.W., Verheijden, J. Lindeman, E., Verschuren, O. Parents' experiences with physical and occupational therapy for their young child with cerebral palsy: a mixed studies review. Child: Care, Health and

Development: 2014, 40(6), 787-796
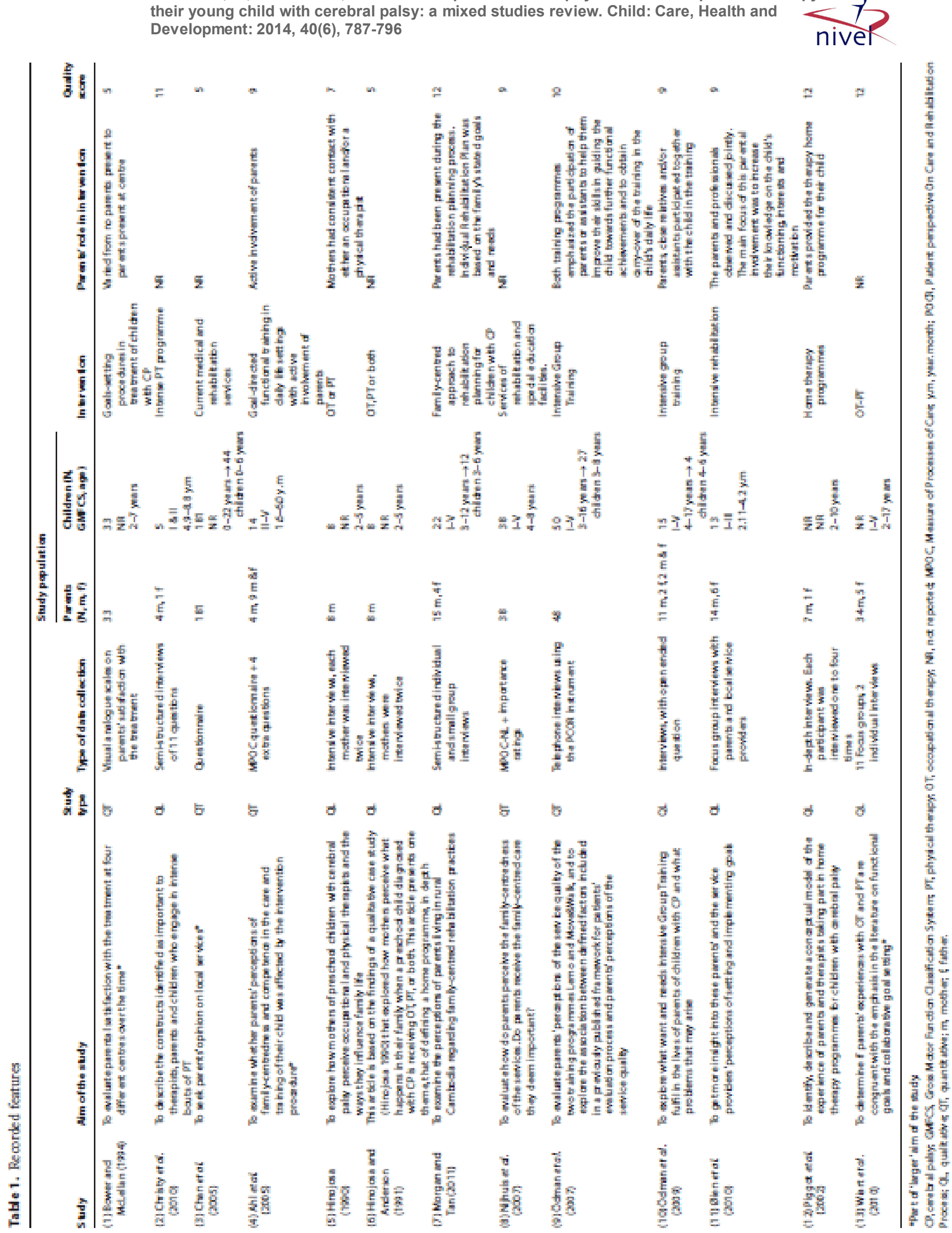
Kruijsen-Terpstra, A.J.A., Ketelaar, M., Boeije, H., Jongmans, M.J., Gorter, J.W., Verheijden, J. Lindeman, E., Verschuren, O. Parents' experiences with physical and occupational therapy for their young child with cerebral palsy: a mixed studies review. Child: Care, Health and Development: 2014, 40(6), 787-796

TABLE 2 THEMES

\begin{tabular}{|c|c|c|c|c|}
\hline & Theme & & Elucidation & Study \\
\hline \multirow[t]{6}{*}{ Context } & \multicolumn{2}{|l|}{ Culture } & $\begin{array}{l}\text { The nature of parents' culture can be reflected in their responses. For example, in the } \\
\text { hierarchical Cambodian culture it was not appropriate for parents to question or } \\
\text { challenge staff about the treatment their child was receiving }\end{array}$ & 7 \\
\hline & Community & Support from others & $\begin{array}{l}\text { Receiving circumstantial support helps parents in striving to maximize their child's } \\
\text { potential while maintaining themselves and their family }\end{array}$ & 10,12 \\
\hline & \multirow[t]{3}{*}{ Family } & Support from family & $\begin{array}{l}\text { Receiving support from family allows parents to have a break from care giving and } \\
\text { to know that their child would not only be looked after but would be working on } \\
\text { skills as well }\end{array}$ & 12 \\
\hline & & Shared responsibilities & Shared responsibilities within family and relatives & 10 \\
\hline & & Roles within family & $\begin{array}{l}\text { Roles within families differ, for example not all fathers actively participated in their } \\
\text { child's therapy, but provided companionship, emotional support and understanding }\end{array}$ & $8 ; 12$ \\
\hline & \multicolumn{2}{|c|}{ Demands of everyday life } & $\begin{array}{l}\text { Parents were balancing the child's therapy with the demands of everyday life. They } \\
\text { sometimes did forego therapist recommendations to keep up with their family } \\
\text { commitments or to enjoy family life }\end{array}$ & $2 ; 5 ; 6 ; 10 ; 12 ; 13$ \\
\hline \multirow[t]{17}{*}{ Process } & \multicolumn{2}{|l|}{ Co-ordinated care } & $\begin{array}{l}\text { Parents expressed the need for better co-ordinated care, for example to limit the } \\
\text { number of visits to different clinics and hospitals }\end{array}$ & $3 ; 4 ; 8$ \\
\hline & \multicolumn{2}{|l|}{ Comprehensive care } & Need for comprehensive care & $4 ; 8$ \\
\hline & \multicolumn{2}{|l|}{ Continuity of care } & $\begin{array}{l}\text { Need for better continuity of care, regular therapy visits by someone who knows child } \\
\text { and family well }\end{array}$ & 3;12 \\
\hline & \multicolumn{2}{|l|}{ Dedicated time } & $\begin{array}{l}\text { Parents perceived it highly important that the therapists had time for communication. } \\
\text { Furthermore they wished to have more frequent follow-up for their children and a } \\
\text { longer time allocated for meetings with staff to discuss findings of the assessment } \\
\text { and rehabilitation plan, as well as to have a more detailed assessment summary }\end{array}$ & 3;9 \\
\hline & \multicolumn{2}{|l|}{ Information } & $\begin{array}{l}\text { Parents wanted to have information and knowledge on a range of issues including } \\
\text { their child's abilities and disabilities, future outlook and treatment possibilities }\end{array}$ & $7 ; 8 ; 9 ; 10 ; 11 ; 12 ; 13$ \\
\hline & \multirow[t]{8}{*}{$\begin{array}{l}\text { Family-professional } \\
\text { Partnership }\end{array}$} & $\begin{array}{l}\text { Time to develop } \\
\text { relationship }\end{array}$ & $\begin{array}{l}\text { With time and understanding, parents gained the self-confidence to appreciate the } \\
\text { importance of their own input in decision-making and had enough trust in their } \\
\text { relationship with their therapist to feel content to share the responsibility and be } \\
\text { honest in their feedback }\end{array}$ & 12 \\
\hline & & Shared decision-making & $\begin{array}{l}\text { Parents and therapist share responsibilities in decision-making. Balancing the extent of } \\
\text { guidance parents preferred and the input they received from therapists. With parents } \\
\text { as experts on their child, or leading in goal-setting }\end{array}$ & $7 ; 11 ; 12 ; 13$ \\
\hline & & $\begin{array}{l}\text { Respect and trust by } \\
\text { partners }\end{array}$ & $\begin{array}{l}\text { Respect and trust are requisite for a good family-professional relationship. If these were } \\
\text { not established, parents tried to keep up appearances }\end{array}$ & $3 ; 4 ; 7 ; 8 ; 12$ \\
\hline & & Open communication & $\begin{array}{l}\text { Parents appreciated sharing reflections and constructive feedback, and wanted to be } \\
\text { asked about their expectations }\end{array}$ & $6 ; 7 ; 9 ; 11 ; 12$ \\
\hline & & Responsibilities & Parents wanted to share responsibilities & 10,12 \\
\hline & & Support & $\begin{array}{l}\text { Parents wanted to receive supportive care by the therapists. Lack of support challenged } \\
\text { interactive collaboration }\end{array}$ & $3 ; 4 ; 5 ; 7 ; 8 ; 9 ; 11 ; 12$ \\
\hline & & $\begin{array}{l}\text { Enabling (to make own } \\
\text { decision) }\end{array}$ & $\begin{array}{l}\text { Parents were enable to make their own decisions, for example in taking the lead in the } \\
\text { goal setting process }\end{array}$ & $4 ; 8 ; 11$ \\
\hline & & Collaboration & $\begin{array}{l}\text { Parents and therapist collaborated in the assessment and evaluation of their child as } \\
\text { well as the planning and implementation of rehabilitation, including the choosing of } \\
\text { rehabilitation goals. On the other hand some parents expressed that there are things } \\
\text { that mothers do and things that therapist do }\end{array}$ & $6 ; 7 ; 11 ; 12 ; 13$ \\
\hline & \multirow[t]{4}{*}{ Intervention } & $\begin{array}{l}\text { Implementation } \\
\text { intervention at home }\end{array}$ & $\begin{array}{l}\text { Parents tried to implement their child's interventions or integrate their goals in daily life } \\
\text { at home. However, difficulties were perceived, therefore interventions were adapted } \\
\text { by parents or only partly implemented }\end{array}$ & $5 ; 6 ; 11 ; 12 ; 13$ \\
\hline & & $\begin{array}{l}\text { Therapist-child } \\
\text { relationship }\end{array}$ & $\begin{array}{l}\text { Parents perceived it highly important that the therapists understood the child's most } \\
\text { important problems and needs, and that the therapist had their child's best interests } \\
\text { at heart }\end{array}$ & $5 ; 9 ; 12$ \\
\hline & & Design & $\begin{array}{l}\text { The design of an intervention influences parents experiences, for example an intense } \\
\text { intervention allowed a time of rest and no therapy between sessions }\end{array}$ & $2 ; 10$ \\
\hline & & Content & $\begin{array}{l}\text { Parents got engaged in implementation by short-term, realistic, small and achievable } \\
\text { goals. Not all parents saw a connection between therapy goals and their own goals } \\
\text { for their children. Some parents wanted to focus on functional outcome, others on } \\
\text { quality of their child's movements }\end{array}$ & $11 ; 12 ; 13$ \\
\hline \multirow[t]{6}{*}{ Outcomes } & \multirow[t]{2}{*}{$\begin{array}{l}\text { Child health and } \\
\text { well-being }\end{array}$} & Improvements & $\begin{array}{l}\text { Improvements in for example: functional outcome, vitality and strength, self-confidence, } \\
\text { motivation, motor function, attainment functional goals, independence, } \\
\text { developmental gains, making progress, participation in community }\end{array}$ & $2 ; 5 ; 9 ; 10 ; 11 ; 12$ \\
\hline & & Negative & The intense nature of the programme caused fatigue & 2 \\
\hline & \multirow[t]{2}{*}{ Parental outcomes } & Positive & $\begin{array}{l}\text { Positive parental outcomes were for example: able to see progress, improved } \\
\text { confidence, motivation, knowledge } \& \text { understanding, widened perspective, increased } \\
\text { competence, increasingly effective in goals setting, time with the child, participation } \\
\text { in community }\end{array}$ & $2 ; 4 ; 6 ; 7 ; 10 ; 11 ; 12$ \\
\hline & & Negative & $\begin{array}{l}\text { Negative parental outcomes were for example: feelings of insufficiency, lack of } \\
\text { confidence, lost hope when goals were not reached, feeling guilty, feeling unsure }\end{array}$ & $7 ; 10 ; 12$ \\
\hline & \multicolumn{2}{|l|}{ Increased access } & Parents suggest a better access to existing services: more flexibility in arranging & 3 \\
\hline & \multicolumn{2}{|c|}{ Increased satisfaction with care fllh } & $\begin{array}{l}\text { appointments, shorter waiting list and waiting time, longer consultation time } \\
\text { the therapists }\end{array}$ & $1 ; 3 ; 4 ; 5 ; 12$ \\
\hline
\end{tabular}

(1) Bower \& McLellan 1994; (2) Christy et al. 2010; (3) Chan et al. 2005;(4) Ahl et al. 2005; (5) Hinojosa 1990; (6) Hinojosa \& Anderson 1991;(7) Morgan \& Tan 2011; (8) Nijhuis et al. 2007;

(9) Odman et al. 2007; (10) Odman et al. 2009; (11) Øien et al. 2010; (12) Piggot et al. 2002; (13) Wiart et al. 2010 (italic: qualitative study; bold: quantitative study). 
Kruijsen-Terpstra, A.J.A., Ketelaar, M., Boeije, H., Jongmans, M.J., Gorter, J.W., Verheijden, J. Lindeman, E., Verschuren, O. Parents' experiences with physical and occupational therapy for their young child with cerebral palsy: a mixed studies review. Child: Care, Health and Development: 2014, 40(6), 787-796

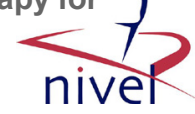

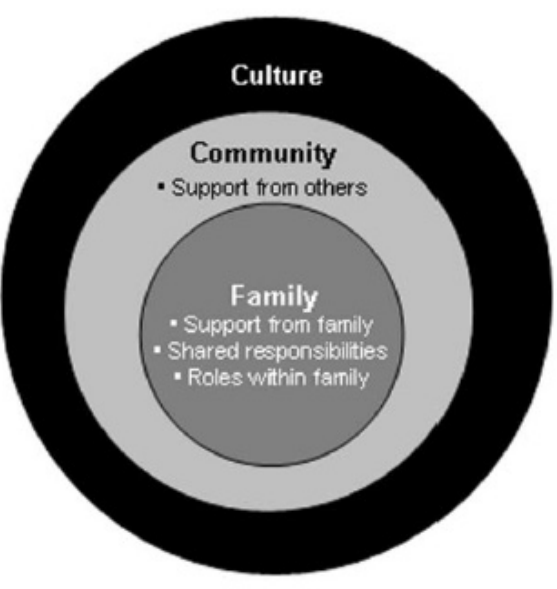

- Demands of everyday life

\section{Context}

\section{Process}

Child health and well-being - Improvements

- Negative

Parental outcomes

- Positive

Increased access

- Implementation intervention

at home

- Therapist-child relationship

- Design

- Content

- Co-ordinated care

- Comprehensive care

- Continuity of care

- Dedicated time

- Information

Increased satisfaction

with care

Figure 3. Framework to describe experiences of parents of young children with cerebral palsy on their child's intervention. 